\title{
Indigenous Ways of Knowing as a Philosophical Base for the Promotion of Peace and Justice in Counseling Education and Psychology
}

\author{
Lisa Grayshield - Washo and Anita Mihecoby - Comanche \\ New Mexico State University
}

\begin{abstract}
Nowhere in my language can I find support to bring an increased awareness of the current life challenges that exist today. Internal Peace in our individual lives and external Peace for our communities and our world entails that we ourselves be peaceful people. I once asked my elders to translate the word peace in our language. They looked at each other thoughtfully, bewildered at my inquiry, smiled and replied in agreement, digum hi'ki 'angaw hulew' (Let's all get along and respect one another). Peace in my language is not an abstraction. Peace happens when everyone is working together in a way that benefits everyone including those yet to come. In this way there is no mistake. Peace is not just a state of being, or doing, it is both. It is who we are. It is based on respect for one another. From this consciousness we can create a beautiful world for everyone. As a Washo Native American scholar I share my experience in Western academia, describe the inconsistency between the praxis of Indigenous Ways of Knowing and that of the field of counseling psychology. I share the way that I know how to make a better world for all by acknowledging the significance of Indigenous perspectives on counseling psychology in theory, research, and practice.
\end{abstract}


digum hi:ki 'angaw hulew, let's all get along and respect one another. When I asked my

Elders how to say Peace in our language, this is what they told me, digum hi:ki 'angaw hulew

\section{Introduction}

After graduating with a Ph.D. in counseling and psychology, from a Western education system, I accepted a position as an assistant professor in a program that was very much like the one I had left. I soon found myself as frustrated negotiating the halls of academia as a professor as I had been when I was a student. Only now I have the added responsibility of assisting students through the same frustrations I thought I had overcome. The challenges in doing so are intricately woven in the very paradigm with which I received my Ph.D. Something was not working and I simply could not articulate what it was. I knew I could argue the need for multicultural competence and social justice, not only based on the lack of it from my personal and professional experiences, but as evidenced in the literature (Arredondo et al., 1996). While the challenges of diversity are well documented, the question of competency still remains. Through extensive literature review, dialogue, reflection and experience, I have become profoundly aware of the dichotomous relationship that exists within myself as an Indigenous/Tribal person and a counseling educator.

This manuscript is my attempt to share the processes that have led me to the inevitable deconstruction of my identity as a counseling educator, service provider, and researcher in this field. My intent is to share with you the way that I know how to make a better world for all. I am not attempting to provide another model for praxis or theory from which to argue Indigenous verses non-Indigenous. My intentions are not to further the colonization process through application of theory that fails to recognize our collective responsibility to the land, the air, the water, or to future generations. I simply want to share with you some of the things that have brought me back to my culture to define my work as an Indigenous scholar.

The primary purpose of this manuscript is to acknowledge the significance of Indigenous perspectives on counseling psychology in theory, research, and practice. The word Indigenous is used in this manuscript to refer to all people who make claim to a historical continuity of a culture endemic to their native territory that developed prior to civilization, which includes the Washos. Washo refers to my specific Indigenous culture and does not generalize to include other Indigenous tribal communities. Indigenous ways of knowing (IWOK) is an epistemology that recognizes the interconnectedness of all things.

The following entails my attempt to articulate the processes that I have undergone in reaching some of the serious conclusions that I have regarding the field of counseling psychology. Following is an extremely brief historical overview of Indigenous research, Indigenous ways of knowing and Washo culture. Then I attempt to explain a few of the concepts that form the basis of the epistemological view of Washo Ways of Knowing as I understand them. I end with 
some final thoughts on the transformative influence IWOK could have on the field counseling psychology.

\section{Indigenous Scholarship}

I chose the field of counseling education and psychology because I believed it to be a way to learn how to best help my people and myself in this time of change. With the achievement of the highest degree obtainable in the field, completing my first four years as a college professor, and contributing scholarship in numerous venues, it is frustrating to admit that I still cannot state precisely what multicultural competence and social justice in counseling psychology would effectively look like for my people [Washo]. After a lengthy initiation into the culture of academia and scientific research, I find that the depth and breadth of knowledge formation in the academic world is limited to political and economic notions of happiness through pursuits that disregard the damage it brings to the lives and life ways of other beings on the planet. After extensive examination of the literature on Indigenous knowledge forms and ways of constructing knowledge, I have come to some very profound realizations. The very paradigm that informs counseling psychology [Western European, empirically-based science] has become the agent of structuralism in promotion of mental health that is solely focused on well-being at the human behavioral/cognitive level for the purpose of maintaining the structure that created it. I can only conclude that those who find it useful have a conception of the world that holds little connection to the whole of life.

As I contemplate the meaning behind my own work as a counseling educator, service provider, and researcher, I question its relevance. I am conflicted: Do we continue to debate the same issues that arise from a purely Western European paradigm, issues such as racism, sexism, classism, and so on? Or do we go beyond the limits of imposed value structures that have been established by our profession to find better ways to inform our praxis? I have come to a standstill in my career, presented with an irreconcilable difference that must be addressed if this field and the praxis that underlies its basic assumptions are to be considered a viable avenue in making a better world for all. More honestly stated, from my perspective, as a Tribal Indigenous person and human being on this earth, unless a radical shift in paradigm praxis takes place in the field of counseling psychology, it will remain both irrelevant and a tool for further colonization of Indigenous/Tribal people as well as for those who seek an existence based on peace for all beings on the planet.

After an exhaustive literature search of Indigenous methods across numerous academic fields, I learned that the challenges I face are similar to those being voiced by other Indigenous scholars around the world. Linda Tuhiwai Smith (1999), in her book Decolonizing Methodologies; Research and Indigenous Peoples, lays the groundwork for an Indigenous research agenda to address issues of justice and equality. Smith acknowledges the conditions that Indigenous communities live through: survival, recovery, acclimation, and selfdetermination. Smith associates these conditions to the processes that Indigenous scholars experience as they attempt to embark on their own journey as a teacher, researcher and provider of relevant services to and for the larger academic community, especially when issues arise that conflict with Indigenous/Tribal conceptions of the world. 
Martín-Baró (1987) outlined the constructs of a liberation psychology that maintains that oppressed people become agents of their own history. He assigns three urgent tasks in the process of freeing the mind to be able to think outside the current colonial power structures. The three tasks include: 1 ) the recovery of historical memory; 2) de-ideologizing everyday experience and social reality; and 3) utilizing the virtues of the people. All three tasks require direct engagement by the people and for the people. It is no longer acceptable to assume that the answers to the challenges posed for the next generation regarding how to best live in this world will be found among the same systems that created them. The challenges concern the dichotomy between Indigenous and colonial mentality, Indigenous ways of knowing and Western scientific research. According to Indigenous scholar Marie Battiste (2002), the task of Indigenous academics is to affirm and activate the holistic paradigm of Indigenous knowledge to reveal the wealth and richness of Indigenous languages, worldviews, teachings and experiences.

Therefore, the following is my first attempt to share the knowledge that I am privileged with as a Washo/Indigenous Tribal person. I make no claim to "know" the Washo Way, I write as one person who is Washo. I am writing this article from an Indigenous/Tribal perspective, having been born and raised in my Tribal community, as well as from the perspective of one who has been initiated into the world of scientific Western scholarship. I realize that my most valuable and effective contributions to the field are indeed the perspectives that were shaped from my cultural background, as numerous writers and researchers of multicultural competence and social justice assert.

\section{Studying the Indigenous}

Pan-Indian generalizations about "Native Americans" abound in the literature. However, true and accurate knowledge about Tribal/Indigenous people can only be gained through extensive exposure and interactions in the specific community from where that knowledge originates. It is simply not enough to know about Indians, be part Indian, take a class, or have an insatiable curiosity about them. In an essay on principled and ethical perspectives and research with North American Indian communities, Trimble (2008) postulated that before anyone can begin to apply conventional psychological principles and theories to an ethnocultural group, they must first understand its unique life ways and thought ways. There are, however, some generalizations that can be drawn from the very fact that they, or rather "we" in the larger sense of the word still do exist and continue to practice our cultural ways, our sacred ceremonies, and continue to speak our unique tribal languages regardless of the numerous attempts to assimilate "us" into the dominant value system.

\section{Recognition of Indigenous Ways}

Deloria, Jr. (1993) stresses the importance of new insights derived from other sources while noting that the ability of scientific thinkers to move beyond their comfortable and accepted methodologies is pending. Writers and researchers are recognizing that Indigenous people have ways of viewing the world that extends beyond the Western European paradigm. For example, Lumpkin (2001) recognizes knowledge formation, according to Indigenous/Tribal groups, functions in a polyphasic conscious realm--or diverse and transrational altered states of consciousness - that incorporates a variety of perceptual processes that value the whole of 
biodiversity. She refers to transrational states of consciousness such as meditation, trance, dreams and imagination as key elements in understanding diverse paradigms. Lumpkin further states that societies that place a high value on a variety of conscious perceptual processes are "better stewards of their environments because they grasp the value of the whole of biodiversity (biocomplexity) as well as scientific processes leading to a higher degree of adaptability and evolutionary competence (p. 37). Fixico (2003) stated that "Indian thinking is inquiry into relationships and community, and it reminds us that community extends beyond human relationships" (p. 7). Relationships solely focused on human interactions are devoid of the complexity of relationships that converge to inform a way to think about the world that includes a multi-logical theoretical perspective. Multi-logical thought suggests that knowledge is highly subjective and fluid. Cajete (1994) described an Indigenous education as a process of tracking, "Learning how to blend the mythological, aesthetic, intuitive, and visual perspectives of nature with the scientific, rational, and verbal perspectives..." (p.123). The field of counseling psychology would benefit greatly from this kind of information and from those whose thinking style naturally accommodates a multi-logical view of the world. Abraham, (1994) in his description of the Orphic trinity in science, described three streams of scientific knowledge that converge hermeneutically in an inevitable evolutionary change in consciousness that could have profound effects on the way we view our roles as counseling educators and psychologists. Abraham's multi-logical theoretical approach involves 1 - the chaos revolution originating in the physical sciences; 2 - the gaia hypothesis which began in the biological sciences; and 3 erodynamics which began in the social sciences. He described this convergence as interacting in resonance, "constituting a model for the planetary mind that may even be nature herself" ( $p$. 18). Laszlo and Krippner (1998) described an evolutionary systems design, offering hope to the creation of sustainable evolutionary pathways that allow all beings - including the earth's life support systems - to evolve sustainably with dignity and harmony. If it is a stretch for some readers to grasp the gist of what I am trying to communicate, it may be simpler stated as linking our perceptions of personal life processes and self-actualizations to our relationships, or lack of relationships, with nature and the ecological environment for which we live. The following commentary will provide an overview of the literature that attempts to share the perspectives of Indigenous ways of knowing from the most general epistemological vantage.

\section{Indigenous Ways of Knowing}

There are no "known" forms of knowledge in the Indigenous conception of the universe. What can be known is always subjective and in constant change regardless of empirical scientific evidence. Vine Deloria Jr. (1999) concluded that knowledge is a result of keen observations in the experience of daily life and in the interpretive messages received from spirits in ceremonies, visions and dreams (p. 64). Deloria postulated that reality for tribal people includes the experience of the moment coupled with the interpretive scheme that had been woven together over the generations. The field stands much to gain from the knowledge of Indigenous cultures whose conscious awareness of life have maintained thousands of years of existence on this land without wide scale violent acts of war, or causing harm to their respective environments. This basic understanding is the epistemological and ontological paradigm of an Indigenous thought process; it is the Indigenous Way of Knowing (IWOK). From this paradigm, counseling psychology would naturally promote engagement in activities that increase one's awareness of nature as a basic and fundamental construct of health and well-being. 
A complex matrix of holistic awareness of the whole of life is at the heart of an Indigenous paradigm. Indigenous Ways of Knowing (IWOK) has served as a cornerstone for addressing the challenges of global climate change and eco-sustainability, and is receiving increased attention in a variety of academic disciplines such as anthropology, sociology and psychology (Denzin, Lincoln \& Tuhiwai Smith, 2008). Chief Seattle stated the basic philosophic stance underlying IWOK in his response to the U. S. governments demand for ownership of the land in the 1850 treaty negotiations, "This we know, that all things are connected like the blood that unites us. We did not weave the web of life we are merely a strand in it - whatever we do to the web, we do to ourselves" (Jeffers, 1991). This is true for all relationships on the planet from the simplest life forms, to human interactions, to solar planetary systems.

Indigenous knowledge has been defined as a multidimensional body of lived experiences that informs and sustains people who make their homes in a local area and always takes into account the current socio-political colonial power dimensions of the Western world (Denzin et al., 2008). The literature identifies three central features within Indigenous knowledge that have both political and curricular implications: many Indigenous/Tribal cultures related harmoniously to their environment, experienced colonization, and provided an alternative perspective on human experience that differed from Western empirical science (p. 144). This definition of IWOK refers to numerous forms of knowledge construction by Indigenous/Tribal groups that have allowed them to maintain their existence in a specific locale over time. This includes the combined paradigms of their epistemologies, ontologies, and cosmologies that construct ways of being and experiencing in relationship to their physical surroundings (Kincheloe \& Steinberg, as cited in Denzin et al., 2008).

The most profound literary account of IWOK that has proven practical in many different aspects for today's world is represented in the Mayan calendar. Jose Arguelles (1987), in his book The Mayan Factor, describes the science of the "stone age people" called the Maya as far superior to that of modern science. Mayan science according to Arguelles goes beyond the material cognitive constructs of modern science into a deeper and more meaningful understanding that is based on harmonic resonance, an "invisible galactic life thread" that link people, the planet, the sun, and the center of the Galaxy. A society whose ways of knowing are based on harmonic resonance recognizes the influence of numerous constructs including the senses and levels and frequencies of synchronized intelligence from altered states of consciousness to the smallest particle of matter to the vastness of the universe itself (Arguelles, 1987). From Arguelles' description of Mayan ways of knowing, psychology might stand to gain tremendous advances by recognizing factors associated with harmonic resonance and mental constructs of resistance. The "goal" of counseling psychology may be to assist with the process of reaching a balanced state of being, thus recognizing to what avail the resonance of therapeutic intervention has on a client.

In an attempt to inform counseling psychology, researchers should look outside of the field to glean information from other disciplines that have studied extensively the works of Native/Indigenous people and healers. New fields of study such as neuropsychology, psychoneuroimmunology, and biocolonialism have emerged to explain the processes that Indigenous/Tribal people and their spiritual people have undergone in their work. Numerous alternative stress reduction techniques are based on reaching a still and peaceful mind through listening to the sounds of nature, spending time in the fresh air and getting away from the 
hustle and bustle of a busy life. I find it interesting that science has come to similar conclusions about the benefits of human relationships to nature through technological evidence regarding the sounds of nature and brainwave patterning.

It is not much of a stretch to imagine our understanding of health and well-being in the academy to include relationships that are tied to the beginning of time, extending beyond human actions and interaction. With this understanding, "we", as a human race, would be a catalyst to the promotion of a sustainable world for generations to come. If the entirety of the human condition, the earth, the water, and the sky was viewed as a living breathing conscious being whose life force is intricately interwoven with one another, then concepts of love, beauty, and peace would be common in the English language. Counseling psychology as an extension of this paradigm would be an intellectual pursuit to act upon the world in such a way that our grandchildren's grandchildren would experience the natural beauty that is our land.

Denzin et al. (2008) wrote the first handbook of critical and Indigenous methodologies to challenge the academy's notion of "normal science" with the questions that are raised about the nature of our existence, our consciousness, our knowledge production, and the "globalized," imperial future that faces all people on the planet at this historical juncture (p. 136). From a number of academic disciplines, this handbook outlines a praxis based on IWOK specifically as a resource for any justice-related attempt to bring about social change. I highly recommend this text as a foundation to any discipline that promotes multiculturalism, diversity and social justice.

\section{Indigenous Medicine and the Future}

The beauty of Indigenous ways, tribal medicine people, and their practices is increasingly enchanting young people by the thousands and of all races. Anthropologists have been following these movements since its inception as an academic science. It has not only produced a faddish new age form of spiritualism, it has produced a counterculture of new young intellectuals whose lives threaten the existing status quo through their pursuit of Indigenous forms of knowledge with which to understand the world of which they now find themselves a part. Indigenous medicine people have become the subject of numerous academic books, articles and master's theses and dissertations.

Our medicine people, Wa:shiw daMomLi', practiced medicine in a way that brought about healing through intention. While the symptoms were "treated" with numerous forms of interventions, the underlying "cause" for the "illness" was always at the soul level. To alleviate "pain" - physical, psychological and/or emotional - largely depended upon the intentions (whether conscious, subconscious, or altogether unconscious) of the individual and/or their environmental associations. Therefore, medicine was "practiced holistically, addressing the body, the mind, the emotions, and the spirit. Treatment itself is based purely on consciously changing the "reality" the individual has created for themselves. There is no "individual" in Indigenous medicine, if one is suffering, then all will soon be suffering. Therefore, "diagnosis and treatment" was holistic, and "healing" depended largely on everyone and anyone involved in the individual's life. Being well is in the best interest of everyone, be it plant or beast. 


\section{Indigenous "Standards" of Practice}

Indigenous standards of practice are largely based on the relationships that we establish with each other as well as those with our surrounding environments. IWOK is simply conscious and mindful living. Ervin Laszlo (1987; Abraham, 1994) the founder of systems philosophy and general evolution theory described the changes that must be taken on a personal, national, and international scale in addressing the challenges that we face on a worldwide scale politically as well as environmentally. He describes the benchmarks of an evolved consciousness that includes safeguarding the intrinsic right to life and to an environment supportive of life for all the things that live and grow on Earth as well as the pursuit of happiness, freedom, and personal fulfillment in harmony with the integrity of nature and with consideration for the similar pursuits of others in society with attention to one's neighborhood, country or region and the whole of the biosphere.

\section{Historical Overview of The Washo}

Washi:shiw, (the people) have lived and still live in and around the heart of our original traditional/tribal homelands - Da'aw 'a:ga'a (Lake Tahoe). The boundaries of Washo territory were vast according to Joann Nevers (1976), one of my relatives who wrote WA SHE SHU: $A$ Washo Tribal History. She writes that Wa'she'shu' $E$ Deh (Washo lands) and ways of life extend along the western slope of what is known today as the Sierra Nevada Mountain Range to the eastern slope of the Pine Nut Hills, also known as the Virginia Ranges. Honey Lake is to the North, and Sonora Pass to the South.

The history of my people according to Western science's latest estimates extends 9,000 years in the Lake Tahoe Basin and adjacent east and west slopes and valleys of the Sierra Nevada Mountain Range. Lake Tahoe is the spiritual and cultural center of our world. Protecting the lake and surrounding homelands have been and continue to be a primary cause for my people. "The health of the land and the health of the people are tied together, and what happens to the land also happens to the people. When the land suffers so too do the people" (A. Brian Wallace, Former Chairman of the Washo Tribe, 2004).

Growing up, I listened to countless talks, teachings and stories by Tribal members who stated that our people, the Washo, have lived on the land since time immemorial; that we have always been a small tribe, and that our ways have always been peaceful. Our creation stories clearly convey that we were always smaller than the surrounding Tribes. Our stories tell us that we came from the stars, damolo:sung gum t'anu (our relatives from the stars) and that our relatives are still there. The creator of our people is a woman, Nent'ushu'. Nent'ushu', the old woman from the stars who gave a basket of seeds to a coyote. She instructed the coyote to open the bag when he reached the Washo's valley. Before coyote reached the valley, many of the seeds began to fight and jumped out of the bag. These seeds became the surrounding Tribes, the Paiutes and the Shoshones. The seeds that were left in the bag did not fight, they were peaceful, and while there were only a few left, they were good-looking and strong! These become the small tribe of Washos that is my people. In a paper by Warren L. d'Azevedo (1993), unreliable census figures estimated that our Tribe numbered only 1,500 at the time of contact (around 1840) and decreased to 150 to 800 by the turn of the twentieth century due to white occupation. 


\section{Contact Colonization and Historical Trauma}

The primary decline of my people and their traditional ways of life started in and around the mid 1800's with the discovery of silver and gold near Virginia City. Miners from California rushed to create what is historically known as the Comstock Lode, bringing thousands of colonizers to Washo Territory and ending Washo life as was known for thousands of years prior (d'Azevedo, 1993; Fowler \& Fowler, 2002; Nevers, 1976). It is surreal to try and comprehend that my people sustained their lives and life ways for thousands and thousands of years without significant disruption, and yet in a very short period of time, less than one hundred and seventy years, not only has the ways of life changed drastically, so has the land. The level of destruction to our lake and the surrounding lands since the time of contact has been profound. Equally profound has been the impact on the people that have lived on this land since time immemorial. While my people have remained peaceful, the resistance to white colonization is evident prevalent in the numerous health discrepancies that exist in our communities.

After numerous trips to Washington D.C. by Tribal leaders to petition the federal government for Tribal recognition, we became an officially recognized Tribe of Indians in 1934. Federal recognition afforded us the opportunity to advocate for ourselves from the perspective of a colonized group of people with sovereignty status. Sovereignty, according to definition, includes freedom from outside interference and the right to self-government. The Bureau of Indian Affairs (BIA) is the branch of the government that was established to address the relationships between Tribes and the state and federal governments that occupied their territories. However, most of us believed that the BIA existed to keep the arguments going between the people and the government instead of solving anything. We were never assigned a reservation like other Tribes, and most of us now live in or around one of four colonies. They are known today as the Reno/Sparks Indian Colony, the Carson Indian Colony, the Dresslerville Colony and the Woodfords Colony.

\section{Washo Language and Culture}

While my people historically had some contact with the surrounding tribes, they were clearly distinct from them in their cultural activities, spirituality, and language. It is commonly accepted among Indigenous/Tribal people that language is key to understanding our culture. It is easy to ascertain from the anthropological records of my people that our ways were not fully understood, and certainly not comparable to that of the Western European world. The Washo language was categorized linguistically as being in the Hokan language family, as opposed to the larger Uto-Aztecan language families of their surrounding neighbors, the Paiute and the Shoshone. Linguist and long time researcher and writer of the Washo language, William $\mathrm{H}$. Jackobsen, recorded and documented our language into the international linguistic alphabet. His writings have proven invaluable in this new age of English only. While there is no conclusive record of the number of language speakers that learned Washo as their first language, it is safe to conclude that there are fewer than I would like to say. As an Indigenous people group of the Americas, we are in an extremely fragile state. Throughout my life, I have been involved in numerous Tribal cultural endeavors to "save" or revitalize our language, culture, and traditions. I have been raised with the innate understanding that if we lose our language, we lose our culture. The U.S. government also understood this well in their attempts to colonize our people. 
However, our language continues to be spoken, and the elders of our tribe are held in high regard as keepers of the way. Every time an elder passes, we all feel the loss. I believe it is safe to generalize that many Indigenous/Tribal people have the understanding that language is life.

The key to understanding the world-view of the Washo is intricately related to the concepts that are being conveyed through the language. It would take an enormous effort to explain the differences in Washo and Western world view, and I would need to enlist the services of numerous tribal members in addition to that of a linguist in order to effectively bridge the two opposing world views for Western scientific consumption. The point in this literary exercise is to begin to bridge that dichotomy. The following exemplifies a major Washo concept that differs from the Western approach to social justice that I learned from my ancestors.

I learned about a concept that revealed one way that my people maintained such a beautiful way to live for thousands of years at our annual Tribal culture camp (Lake Tahoe, 2009) while sitting with a group of Washo elders and speakers of the language. The concept of dewhu:Li'a term that referred to the ghost realities - is the things that we know, but do not talk about. It is a concept that encompasses numerous stories of colonization, oppression, destruction, and marginalization experienced by my people. Many of my Washo elders knew this, and while they experienced first hand the stories that we tend to tell over and over, they themselves did not talk openly about them. Thoughts are a manifestation of our souls, that which lies deep within the heart of our stories, our experiences, and the emotions that define them. They understood the power of the spoken word be it English or Washo. The spoken word is the final manifestation of one's creation; it reveals the thoughts that we think about.

I heard my elders explain it this way: mi'lew hute'weh' dew u'hu'li', all of the things we do not talk about. I was reminded of the words of my P'isew (Great Grand Relative) who whenever she did not want to hear about something that she did not want to be true such as alcoholism or domestic violence, she would state emphatically - "I just don't talk about it." In my partly colonized mind, I dismissed this as a simple admonishment - certainly, no one wants to hear about bad things happening. However, as a socially minded individual, I felt it my duty to inform and raise awareness of the concurrent injustice that resulted from inappropriate and unequal practices in dominant society. I strongly believed that the resulting effects of colonization such as drug and alcohol use merited attention by way of raising awareness.

I recall a presentation that I gave at a Tribal council meeting as a young college student. The presentation carefully outlined the timelines of contact with colonizers and the current state of health and well-being in Washo country as evidenced in health and education data and statistics. After a lengthy explanation of disparate treatment and social injustice, one of my elders simply retorted, "Well, we're still here!" They were more concerned that we engage in cultural activities and learn our language than they were concerned about statistics and data on health education disparities between whites and Natives. I remember numerous admonishments from my relatives for speaking of culture but spending little time engaged in it. My elder relatives simply saw no relationship between social justice and raising awareness of disparities through statistical record and commentary; because to them social justice is cultural revitalization. 
At one point in my career I would have considered myself an activist in the most 70's conception of the word. I protested in land disputes, advocated for treaty rights, marched for peace, and fought for equality in educational attainment for our Indigenous youth. My older relatives were not so political by nature. I had not considered that the words my P'isew was speaking were derived from ancient wisdom. I had not considered that her Indigenous/Washo orientation could not effectively be represented in the limited conceptual paradigms of the English language. What my P'isew was conveying was not simply an admonishment for talking about something or someone in a bad way. I later learned that what she was attempting to communicate was a concept that I had not yet understood from my more Western de-evolved mode of thinking. Washos know that we simply cannot bring about justice in cultural communities through our continued commentary on the injustice that exists. In fact, from my cultural epistemological world-view, if we do this, we become catalyst to further colonization. Now, I understand what P'isew was trying to convey when she said "don't talk about it." It was a plea to talk about something we want. Understanding this value of my culture, I now question my approach to my work and whether it reflects who I am as a Washo with this lesson in mind.

Indigenous scholar Vine Deloria Jr., in his interview with "old Teton Sioux Indian" with whom he was describing the Western scientific method describes this concept. Deloria stated that:

There is no difficulty in leading an old Teton Sioux Indian to understand the 'scientific' attitude, and that the processes that give rise to phenomena may be more and more known by man and be, to some extent, controlled by man and that in this way the forces of nature may become a mainspring of progress in the individual and in the human race. The idea of atoms and electrons is easy and pleasing to an old Indian and he grasps the idea of chemistry. Such things make ready contact with his previous observation and thinking.... The world is constantly creating itself because everything is alive and making choices which determine the future. (p. 63)

The real interest of the old Indians, according to Deloria, was not to "discover the abstract structure of physical reality" but rather to "find the proper road along which, for the duration of a person's life, individuals were suppose to walk."

Deloria Jr. goes on to conclude from his research with Indigenous/Tribal elders that "[t]here is a direction to the universe empirically exemplified in the physical growth cycles of childhood, youth and old age with the corresponding responsibility of every entity to enjoy life, fulfill itself, and increase in wisdom and spiritual development of personality." This is true for all relationships according to Deloria's research, including the relationships one develops with nature and spirit. Deloria Jr. further recorded the answer to a question he posed regarding the western scientific view of knowledge formation in which one Tribal chief answered:

Not bad, or untrue, but inadequate to explain among many other things how man is to find and know a road along which he wishes and chooses to make this said progress unless the Great Manitoo by his spirit guides the mind of man, keeping human beings just and generous and hospitable. (p.65) 


\section{The Washo Way of Knowing}

The most obvious difference between Western European ways and Washo ways is the importance placed on our relationships with the natural world and our responsibility to its care for future generations to come, ditdehu lada'eship hulew (all of our lands, we will make them right together with our hands). Social justice for American Indian people means recognizing their unique relationships with the land. It is common among my people to hear someone say they are the land and the land is them. The Washo language is full of terminology that innately exemplifies this fact, for example, di Ma;sh', a term referring to my face, is almost the same as dik Ma:sh, which means 'my Pinenut land.'

While human interactions are important, they are not held above the interactions that take place in the natural environment. We honor these interactions that ultimately determine our ability to sustain our existence as we have for thousands of years, ditdehuya 'esht'ot'oli'a, dik'esha' angawhu gabigi (on Washo lands, we are standing strong), dik'esha 'angawhu gabigi (we will live good all together, we will live together in the future). While confrontation existed and still exists in Washo communities, the sobering effects of large-scale loss by way of colonization always united my people to discuss the importance of being who we are, Washi:shiw 'ahuyi (all of the Washo people standing strong together). My father once told me that I am the sum total of all the survival experiences of my ancestors. In other words, I am here, as I am, a Washo, as a result of the choices that my relations made long ago, mi'lew diye:yelu, all my relations. With this understanding, I know that the collective future of the Washo depends wholly on the choices that I make now, which includes what I do and say about who I am - this is the future that I create. For this I am grateful, mi'lew diye:yelu (all my relations), for the ways that have kept us a unique people into this generation.

\section{My Washo Ways of Knowing}

I grew up on the Carson Indian Colony and have relations on all four colonies. My tribal Indigenous orientation and lived personal experiences have instilled in me the notion of a collective responsibility to all of life. I grew up with the words of my relatives that always acknowledged the creator for the wisdom teachings, Wa:shiw wehigi:get (Washo wisdom) that which allows us to remain on this earth. Prayers contained acknowledgement for the ancestors, mi:lew diye:yelu (all my relations); the creator of all things, hungayungayi det'ugit'uk' (one who looks down from above); and our relations to the skies, damalo:sang gum t'anu (our relatives from the stars). We prayed for hope for future generations to come, hutiwe' e'e:ship (these things you will make right with your hands in the future), perseverance of our traditions, gahamup'aye:s gabishgi (we want our traditions to live on) and reminders to live in a good way, gahamushuk 'angaw k'e', ke'i (go forth in a good way). This concept gahamushuk 'angaw k'e', $k e ' i$ (go forth in a good way) is not a simple salutation, it is a prayer referring to the state of your heart as you journey through life. It refers to the process of living, not the product of living - this was understood. This included all relationships, those that we engage in with each other as well as those that we establish in our everyday life with the earth, the sky, the water, and the air that we breathe. IWOK is an underlying philosophical base that has the potential for adding depth to counseling psychology, which promotes ecological and human sustainability. These are a few concepts that underlie the Washo Way of knowing; Wa:shiw wehigi:get (Washo wisdom). 
The majority of my relatives, my fathers age and older, were recipients of the government boarding schools' assimilation agendas. They were subject to personal, cultural and familial cruelty. However, the vast majority of them did not strike me as angry. While the atrocities that occurred in the process of colonizing were unfounded, it appeared that the anger increased with successive generations. Bonnie and Eduardo Duran (1995) wrote about Post Colonial Stress Disorder (PCSD) as a form of Post Traumatic Stress Disorder (PTSD) to describe the generationally cumulative effects of the Native American experience. PCSD is a "form of ongoing trauma" resulting from forced acculturation whereby Indigenous/Tribal people are under "constant and extreme pressure to assimilate the life world of the perpetrators of their Holocaust" (Duran \& Duran, p. 32). It is helpful to understand from a cognitive standpoint how dysfunction became so prevalent in my community, but the fact still remains, if the approach towards social justice is not about land, language and culture, then the approach is not multiculturally competent.

And so the question remains, do I continue to bring awareness about the injustice that occurred as a result of the colonization process, do I work on more gentle ways to promote social justice through revitalization, or do I become that which I profess, a Washo, and Indigenous scholar with an Indigenous worldview. And if the latter, given the different world-views between Western science and that of Washo, how then do I situate myself as an academician? Reasonably, when one is busy engaged in processes that promote healthy relationships to community, land, language, and culture, then one is naturally in service of self-determination and opposing more oppressive life circumstances in order to render them mute.

My people understood and accepted that there were many things in the universe that simply could not be known. Dak mi:gi'e:s (that which you do not see) refers to all of the things that we could not possibly know, but will be revealed to us when we need the knowledge. In my understanding of this term, it denotes the great mystery. I often heard my elders pray to all the directions, the North, the South, the East, the West, above below and all around. The knowledge gained from such prayers were considered complete and practical because it was produced in consideration of all the elements, life stages, support systems, lessons and processes that promoted good living and sustained a future for generations to come.

Knowledge was highly respected, but the way knowledge was accessed was more important in the Washo conception of life. Knowledge was recognized among my people when it was in service of producing some positive community effect. It was well understood that some people held specific kinds of knowledge that they were privy to as a result of being a member of a certain family or group that was known for their generosity and wisdom in certain aspects of living such as collecting pine nuts, hunting, or when/how to prepare for ceremony or an upcoming harsh winter season.

The Wa'shiw wehigi'get, wisdom of Washo people, is cumulative, derived over thousands of years of existence in which a peaceful life in a small sustainable community living style was apparent. In this way, the elders and the ancestors were held in extremely high regard for the years of observation and interpretation. Respect for elders and the presence of our ancestors, those that came before us, those that are with us today, and those that are yet to come is a given in my community. Knowledge was further validated when it maintained relevance for all, 
including the non-human world. Washos believed that all things were alive and held value from rocks which were used to cook and heat with to willows that agreed to provide certain necessities for the people who cared for them so that they would return. All things are related and intricately interwoven into a web of existence that holds specific meaning and value, whether this was known in a general sense or yet to be discovered when needed. When a person passed on, they did so with dignity and with all respect to the land for which they grew, dit'de'i:'e:s ha' (the one who doesn't leave tracks anymore).

\section{Final Thoughts}

In summary of the concepts that I have discussed in this manuscript, I offer the following definition for a socially just counseling praxis based on Indigenous Ways of Knowing:

Indigenous Ways of Knowing is a praxis that naturally promotes peace, justice, and respect for all life on the planet. IWOK are the collective epistemologies and ontologies of Indigenous people from specific locales that have worked to promote harmony and balance in all directions of their environments: the North, South, East, West, above, below and all around. IWOK is grounded in multilogical reasoning, therefore it naturally considers all things, in all directions, in order to make decisions about how to live on the planet with one another and in promotion of love, beauty and peace for generations to come. IWOK essentially equates to the raising of consciousness from a level of cognitive behavior to one that encompasses actions upon the world to sustain it.

This time in history is marked for great change according to numerous theories and teachings of ancient people who have observed the life cycles of the earth for thousands upon thousands of years. The inception of Indigenous Ways of Knowing would transform the counseling profession in profound ways. A counseling praxis based on Indigenous forms of knowledge would be one that is naturally relevant to the teachings of all earth-based people because the measure of self-actualization would be one that orients individuals to their surrounding environments and their perceived or intended impact on that environment.

When I first began to pursue a higher degree, it was with the hope that I would learn something that would help my people to find better ways to cope with the stresses involved in navigating the Western world. Now, after much consideration and reflection, I find that by helping them do this, together we not only learn how to be more comfortable in this way, we move further from the ways that have maintained our connectedness to the whole of life. The dichotomous construct of living in two worlds is a real dilemma for many Indigenous/Tribal people. It seems that everything we do takes from our environment. Imagine if counseling psychology adopted values that promoted environmental awareness and sustainability as an underlying construct of health and well-being. In this way, one might seek experiences that give them ample opportunity to be in nature, understanding that the experience of walking on this earth is inherently a natural experience in and of itself.

The philosophical foundations of IWOK applied to the methodological constructs of academic disciplines have the potential for transformative sustainable change in human behavior. The field of counseling psychology would do well to yield its cognitive behavioral science to one that 
addresses the needs of the masses at a level of consciousness. The helping profession can become one that is relevant to worldwide global peace, unity and solidarity for generations to come. In this age of globalization and capitalism, the next generation is looking for answers to their future, not further commentary on injustice. Nowhere in my language can I find support for promoting justice threw talking about injustice. My Washo culture taught me that I was an important part of the creation of a beautiful world because I am the land. I believe that to honor those that have gone before me, to respect the ways of my people, and to save a place for future generations to come is my cultural, human, and personal responsibility not only to write but to talk about the world as I want it to be; I must become it - Only love, only beauty, only peace.

Digum hi:ki 'angaw hulew

Contact information/Correspondence:

Lisa Grayshield

New Mexico State University

Email: Ilgray@nmsu.edu

\section{References}

Abraham, R. (1994). Chas, gaia, eros: A chaos pioneer uncovers the three great streams of history. San Francisco, CA: Harper Collins Publishers.

Arguelles, J. (1987). The Mayan factor: Path beyond technology. Santa Fe, NM: Bear \& Company Publishing.

Aron A., \& Corne, S. (Eds.). (1996). Writings for a liberation psychology: Martín-Baró, I., Cambridge, MA: Harvard University Press. London, England. Reprint Original work published in 1994.

Arredondo, P., Toporek, R., Brown, S., Jones, J., Locke, D., Sanchez, J., \& Stadler, H. (1996). Operationalization of multicultural counseling competencies. Journal of Multicultural Counseling and Development, 24, 42-78.

Battiste, M. \& Semeganis, H. (2002). First thoughts on first nation's citizenship: Issues in education. In Yvonne Hébert (Ed.). Citizenship in transformation in Canada. Toronto: University of Toronto Press.

Cajete, G. (1994). Look to the mountain: An ecology of Indigenous education. Skyland, NC: Kivaki Press.

d'Azevedo, W. L. (1978). Straight with the medicine: Narratives of Washoe followers of the Tipi Way. Berkley, CA: Heyday Books. 
Deloria, Jr. V. (1993). If you think about it, you will see that it is true. Noetic Sciences Review, $27,62-71$.

Denzin, N. K., Lincoln, Y. S., \& Tuhiwai Smith, L. (2008). Handbook of critical and Indigenous methodologies. Los Angeles, London, New Delhi \& Singapore: Sage.

Duran, E., \& Duran, B. (1995). Native American postcolonial psychology. Albany, NY: State University of New York Press.

Fixico, D. (2003). The American Indian mind in a linear world. New York, NY: Routledge.

Fowler, D. D. \& Fowler, C. S. (2002). Stephen Powers' "The life and culture of the Washo and Paiutes." Ethnohistory, 17(3/4), 117-149.

Jeffers, S. (1991). Brother eagle, sister sky: A message from Chief Seattle. New York, NY: Dial Books.

Kincheloe, J. L. (forthcoming). Beyond Reductionism: Difference, criticality, and multilogicality in the bricolage and postformalism. Available online at: http://freire.mcgill.ca/articles/node 65/Research/BeyondReductionism.doc. [Date of access: June: 8, 2010.]

Kincheloe, J., Steinberg, S. (1993). A tentative description of post-formal thinking: The critical confrontation with cognitive theory. Harvard Educational Review, 63, 296-320.

Laszlo, E. \& Krippner, S. (1998). Systems theories and a priori aspects of perception. J.S. Jordan (Editor). Elsevier Science.

Lumpkin, T. W. (2001). Perceptual diversity: Is polyphasic consciousness necessary for global survival? Anthropology of Conciousness, 12(1), 37-70.

Nevers, J. (1976). Wa she su: A Washo Tribal history. Salt Lake City, UT: Inter-Tribal Council of Nevada. University of Utah Printing Service.

Smith, L. T. (1999). Decolonizing methodologies; research and Indigenous peoples. New York, NY: Palgrave.

Trimble, J. E. (2008). Commentary: No itinerant researchers: Principled and ethical perspectives and research with North American Indian communities. Ethos, 36(3), 380-383. 